The Astrophysical Journal, 193:157-168, 1974 October 1

(C) 1974. The American Astronomical Society. All rights reserved. Printed in U.S.A.

\title{
ON THE $e$-PROCESS: ITS COMPONENTS AND THEIR NEUTRON EXCESSES
}

\author{
Kem L. Hainebach* and Donald D. Clayton \\ Rice University, Houston, Texas 77001 \\ W. DAVID ARneTt $\dagger$ \\ University of Texas at Austin \\ AND \\ S. E. Woosley \\ California Institute of Technology, Pasadena, California 91109 \\ Received 1974 April 26
}

\begin{abstract}
We analyze the pattern of abundances within the iron-abundance peak, with special emphasis on the isotopes of $\mathrm{Cr}, \mathrm{Fe}$, and $\mathrm{Ni}$, by comparing that pattern with those resulting from the quick cooling of matter initially in nuclear equilibrium (called $e$-process freeze-out). The freeze-out patterns are characterized by the extent to which the material is neutron rich. We calculate the superposition of zones of differing neutron enrichments that gives the best fit to a specified set of abundance ratios. The best one-zone fit to the isotopes of iron is the original $e$-process solution $(\eta=0.071)$, but that solution seriously overproduces $\mathrm{Cr}$ and $\mathrm{Ni}$ isotopes. One-zone solutions without any serious overproductions $\left(\eta \simeq 0.003\right.$, called the low- $\eta$ zone) eject ${ }^{56,57} \mathrm{Fe}$ as ${ }^{56,57} \mathrm{Ni}$ and produce ${ }^{58} \mathrm{Ni}$ instead of ${ }^{58} \mathrm{Fe}$. Best two-zone fits add to the dominant low- $\eta$ zone a high- $\eta$ zone having adequate yields of ${ }^{54} \mathrm{Cr},{ }^{58} \mathrm{Fe}$, and ${ }^{62} \mathrm{Ni}$ to account for their abundances. Three zones cannot substantially improve the fit to the total abundance pattern except in adding ${ }^{60} \mathrm{Ni}$ to the list of successfully synthesized species. No improvement can be obtained by using a superposition of more than three zones. We take these results to be telltale characteristics of the abundances themselves. The need for two zones seems sure. The dominance of the low- $\eta$ zone speaks for a good future for nuclear $\gamma$-ray astronomy, whereas the need for a high- $\eta$ zone should contain important constraints on the dynamics of collapse and ejection. A monotonic continuum of zones gives a poor fit, and the evidence for even a third is not compelling, because ${ }^{60} \mathrm{Ni}$ may be due instead to a low- $\eta$ particle-rich freeze-out.
\end{abstract}

Subject headings: abundances, stellar - gamma rays — nucleosynthesis - supernovae

\section{INTRODUCTION}

Since Hoyle's (1946) pioneering paper, it has been generally agreed that the abundance peak near iron reflects the nuclear properties of the iron nuclei in the following way. The unusually high binding energy per nucleon of ${ }^{56} \mathrm{Fe}$ causes it to be the most abundant species in a thermal equilibrium at temperatures of a few billion degrees if the ratio of neutrons to protons in the gas is sufficiently close to that same ratio in the ${ }^{56} \mathrm{Fe}$ nucleus itself. Burbidge et al. (1957) and Fowler and Hoyle (1964) calculated a rather detailed fit to the abundances of all four iron isotopes, showing that they are reproduced with high precision in a gas having $\eta=\left(N_{n}-N_{p}\right) /\left(N_{n}+N_{p}\right) \simeq 0.07$ and temperature near $T_{9}=3.8$. They called it the $e$-process. The fact that chromium has almost one-fifth the abundance of iron in the same calculation was not regarded as a problem because iron was then thought to be about 5 times less abundant than it is believed to be today. So successful was this calculation that it has been repeatedly cited as one of the outstanding demonstrations of the correctness of the basic idea of nucleosynthesis.

When Bodansky, Clayton, and Fowler (1968) calculated the burning of silicon, they confirmed the Fowler and Hoyle (1964) observation that it preferentially

* Present address: University of Chicago.

$\uparrow$ Present address: University of Illinois, Urbana. synthesizes ${ }^{56} \mathrm{Ni}$ rather than ${ }^{56} \mathrm{Fe}$, because the burning should be too rapid to allow $\beta$-decays sufficient time to increase the neutron excess. Fowler and Hoyle (1964) supposed that $\beta$-decays would subsequently occur while the matter was still held at high temperature so that the equilibrium would shift naturally to the isotopes of iron. Bodansky et al. also discovered that all the $\alpha$-nuclei between ${ }^{28} \mathrm{Si}$ and ${ }^{56} \mathrm{Ni}$ would naturally coexist in approximately their stellar abundance ratios and that, furthermore, most of the nuclei within the iron peak also have about the correct abundance to account for their stable daughters. In particular, the trio ${ }^{54} \mathrm{Fe}$, ${ }^{56} \mathrm{Ni}$, and ${ }^{57} \mathrm{Ni}$ have the appropriate abundances for the natural trio ${ }^{54,56,57} \mathrm{Fe}$. Because so many other species coexisted in favorable amounts, the idea grew that the matter was ejected quickly and that the abundances of the iron isotopes, $A=56$ and 57, reflect instead the nuclear properties of those isotopes of nickel. Clayton and Woosley (1969) made this case even stronger by shifting attention to the most abundant isotope of nickel. They showed that ${ }^{58} \mathrm{Ni}$ will be produced in about the correct ratio to ${ }^{56} \mathrm{Ni}$ if the silicon is quickly and completely burned. On the other hand ${ }^{58} \mathrm{Ni}$ is not produced at all if the material is allowed to become neutron rich, and Burbidge et al. were therefore forced to ascribe ${ }^{58} \mathrm{Ni}$ to their $p$-process. The arguments of Clayton and Woosley (1969) were confirmed and strengthened by subsequent detailed calculations (Arnett, Truran, and Woosley 1971; Woosley, 
Arnett, and Clayton 1973). This sudden ejection of material without neutron enrichment does not, however, synthesize ${ }^{58} \mathrm{Fe}$, so in this alternative another source for ${ }^{58} \mathrm{Fe}$ must be found. Peters, Fowler, and Clayton (1972) discussed this problem in considerable detail, and tentatively decided that a weak $s$-process was not an adequate source. Other sources of these nuclei can be found in other $e$-process zones having differing neutron enrichments, as Clifford and Tayler (1965) showed. Indeed, Truran (1972) has shown that ${ }^{54} \mathrm{Cr}$ and ${ }^{58} \mathrm{Fe}$ may arise from neutron-rich $e$-processes.

The situation has, in fact, become quite complicated. Each differing neutron enrichment results in a different set of nuclei in differing ratios, and one hopes that the sum will account for the whole abundance pattern in this mass range. It is this problem that we attack in this paper. We develop a method for finding the best fit to a given set of abundances with a chosen number of "zones"- our word for mass contributions characterized by differing values of $\eta$. We also develop a numerical method for performing this fit with expanded and cooled zones rather than strictly $e$-process zones. This method is correct for what was called the "normal freeze-out" by Woosley et al. (1973; see especially $\S \mathrm{VII})$. In this case the free light particles $(p, n, \alpha)$ are almost entirely captured during the freeze-out, leading to what we might instead call a " particle-poor freeze-out." Under these circumstances the abundances are reasonably insensitive to the density, and the freeze-out temperature is well defined; therefore the final abundances depend on one parameter $\eta$. This simplification is essential to our analysis. It is by no means obvious that the "particle-rich freeze-out" does not occur in nature; however, in that case the abundances depend upon additional parameters. Our method will also fail if the abundances of some nuclei being fitted are strongly influenced by nuclear processes other than the single one-the particle-poor freeze-out - that we consider here. A consideration of the possible failures of this approach will also be instructive.

This problem has profound implications for astronomy. Clayton $(1973 a, b)$ has reviewed the ways in which the prospects for an entire field of $\gamma$-ray astronomy rest on the radioactive progenitors of abundant stable nuclei. Many empirical tests of nucleosynthesis theory become possible if the appropriate low- $\eta$ zones are ejected. The distribution of high- $\eta$ zones, on the other hand, seems likely to give outstanding dynamical information about the formation of collapsed remnants.

\section{II. $e$-PROCESS FREEZE-OUT COMPOSITIONS}

The compositions discussed in this work are those of material which has probably been at temperatures greater than $T_{9}=5\left[T_{9}=T\left(^{\circ} \mathrm{K}\right) / 10^{\circ}{ }^{\circ} \mathrm{K}\right]$. Above this temperature, the time scale for any initial composition to approach nuclear statistical equilibrium (henceforth referred to as NSE) is smaller than the explosive hydrodynamic time scale, which is on the order of $1 \mathrm{~s}$. Thus NSE will normally be maintained at temperatures above $T_{9}=5$ during an explosive expansion.
The compositions discussed here (called "freezeout" compositions) were calculated by using a nuclear reaction network in a way described fully in Truran and Arnett (1970) and again in Woosley et al. (1973) to follow the evolving composition of material expanding adiabatically $\left(\rho \propto T^{3}\right)$ on a hydrodynamic (free-fall) time scale: $\tau_{\mathrm{HD}}=446 /\left(\rho_{0}\right)^{1 / 2}(\mathrm{cgs})$, where $\rho_{0}$ is the initial density. One then has $\rho=\rho_{0} \exp \left(-t / \tau_{\mathrm{HD}}\right)$, with $T \propto \rho^{1 / 3}$. As the temperature falls below that value required to maintain strong flows from species to species, the nuclear reactions are said to "freeze out." Except for the particle-rich cases mentioned above, such simple prescriptions for evolution in the $(\rho, T)$-plane have been found to be good approximations in earlier hydrodynamic calculations of the ${ }^{12} \mathrm{C}$ detonation model (Arnett et al. 1971) and to reproduce well the resulting compositions. Usually, increasing the time scale by a factor of 10 alters the resulting abundances by only a few percent for the particle-poor freeze-out considered here.

The initial temperature chosen for the present calculations was $T_{9}=5$, since following the reactions at higher temperatures would only be an expensive way of calculating NSE compositions. The initial density was $5 \times 10^{7} \mathrm{~g} \mathrm{~cm}^{-3}$. A variety of initial neutron excesses $(\eta)$ were used. The neutron excess reflects the history of electron capture and other weak interactions in the material. It constrains the set of composition parameters $X_{i}$ to satisfy the relation

$$
\eta=\sum\left(\frac{N_{i}-Z_{i}}{A_{i}}\right) X_{i}=\sum_{i} \eta_{i} X_{i},
$$

where the sum is over all nuclei, $A_{i}$ is the atomic weight of nucleus $i, Z_{i}$ is its atomic number, $N_{i}=$ $A_{i}-Z_{i}$ is its neutron number, and $X_{i}$ is its nucleon fraction $A_{i} n_{i} / \sum_{j} A_{j} n_{j}$, where $n_{i}$ is its number density. The range of $\eta$ is -1 to +1 . The second equality in equation (1) defines $\eta_{i}$, the neutron excess of each nucleus. The nuclear network described by Woosley et al. (1973) was calculated for expansions having neutron excesses $\eta=0.0037,0.037,0.060,0.069$, $0.071,0.0837,0.090$, and 0.100 . Initial compositions were NSE compositions evaluated at the initial $T, \rho$, and $\eta$. The expansions required $\leqslant 1$ s of expansion time for the temperature to fall below $T_{9}=1$.

The resulting abundances appear in table 1 , which lists particle-poor freeze-out abundances, before $\beta$ decay, calculated by the nuclear-burning network at eight values of $\eta$, with initial abundances and conditions as described above. An entry of 0.0 indicates that the nucleus was not included in the network at that value of $\eta$ because its abundance was judged negligible.

The particle-poor freeze-outs discussed here occur when stellar material is more dense than about $5 \times$ $10^{7} \mathrm{~g} \mathrm{~cm}^{-3}$ as the temperature falls to $T_{9}=5$. At lower densities, the "alpha-rich" (i.e., particle-rich) freezeout discussed by Arnett et al. (1971) occurs. The particle-rich freeze-out does occur in the ${ }^{12} \mathrm{C}$ detonation model of Arnett et al.; it is not yet certain to what extent it occurs in other models. In this work, we consider only normal freeze-out compositions and see 
TABLE 1

Nucleon Fractions of Particle-Poor Freeze-outs

\begin{tabular}{|c|c|c|c|c|c|c|c|}
\hline 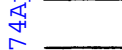 & $n$ & 0.0037 & 0.0370 & 0.0600 & 0.0690 & 0.0710 & 0.0837 \\
\hline $46 \mathrm{CA} 2$ & 20 & $1.065 \mathrm{E}-27$ & $1.668 \mathrm{E}-20$ & $1.579 \mathrm{E}-14$ & $1.089 \mathrm{E}-12$ & $8.889 E-12$ & $7.783 E-08$ \\
\hline $46 \mathrm{SC} 2$ & 21 & 1. $475 \mathrm{E}-19$ & 1. $310 \mathrm{E}-15$ & $9.762 \mathrm{E}-13$ & $6.957 \mathrm{E}-12$ & $1.421 \mathrm{E}-11$ & $1.181 \mathrm{E}-10$ \\
\hline $46 \mathrm{TI} 2$ & 22 & $1.771 \mathrm{E}-07$ & $2.356 \mathrm{E}-06$ & $5.169 \mathrm{E}-06$ & $2.676 \mathrm{E}-06$ & $1.052 \mathrm{E}-06$ & 0.0 \\
\hline $47 \mathrm{CA} 2$ & 20 & 0.0 & 0.0 & $6.769 \mathrm{E}-19$ & $1.434 \mathrm{E}-16$ & $2.636 \mathrm{E}-15$ & $5.677 \mathrm{E}-10$ \\
\hline $47 \mathrm{SC} 2$ & 21 & $3.793 \mathrm{E}-20$ & $2.151 \mathrm{E}-16$ & $8.351 \mathrm{E}-12$ & $1.231 \mathrm{E}-10$ & $4.221 \mathrm{E}-10$ & $8.815 \mathrm{E}-08$ \\
\hline $47 \mathrm{TI} 2$ & 22 & $6.596 \mathrm{E}-12$ & $1.721 \mathrm{E}-09$ & $2.517 E-07$ & $3.092 \mathrm{E}-07$ & $2.218 \mathrm{E}-07$ & $1.721 \mathrm{E}-08$ \\
\hline $47 \mathrm{~V} \quad 2$ & 23 & $2.628 \mathrm{E}-08$ & 0.0 & 0.0 & 0.0 & 0.0 & 0.0 \\
\hline $48 \mathrm{CA} 2$ & 20 & 0.0 & 0.0 & $2.044 \mathrm{E}-20$ & $2.289 \mathrm{E}-17$ & $9.442 \mathrm{E}-16$ & $4.854 \mathrm{E}-09$ \\
\hline $48 \mathrm{SC} 2$ & 21 & 0.0 & 0.0 & $4.096 \mathrm{E}-15$ & $2.128 \mathrm{E}-13$ & $1.621 \mathrm{E}-12$ & $8.059 \mathrm{E}-09$ \\
\hline $48 \mathrm{TI} 2$ & 22 & $1.720 \mathrm{E}-13$ & $4.571 \mathrm{E}-09$ & $3.510 \mathrm{E}-06$ & $2.532 E-05$ & $4.212 \mathrm{E}-05$ & $1.284 \mathrm{E}-04$ \\
\hline $48 \mathrm{~V} \quad 2$ & 23 & $5.284 \mathrm{E}-09$ & $4.560 \mathrm{E}-09$ & 0.0 & 0.0 & 0.0 & 0.0 \\
\hline $48 \mathrm{CR} 2$ & 24 & $2.947 E-04$ & $6.375 \mathrm{E}-07$ & 0.0 & 0.0 & 0.0 & 0.0 \\
\hline $49 \mathrm{SC} 2$ & 21 & 0.0 & 0.0 & $5.315 \mathrm{E}-16$ & $1.511 \mathrm{E}-13$ & $2.722 \mathrm{E}-12$ & $3.611 \mathrm{E}-07$ \\
\hline $49 \mathrm{TI} 2$ & 22 & 0.0 & $8.458 \mathrm{E}-13$ & $8.526 \mathrm{E}-09$ & $1.746 \mathrm{E}-07$ & $6.053 \mathrm{E}-07$ & $3.764 \mathrm{E}-05$ \\
\hline $49 \mathrm{~V} 2$ & 23 & $9.961 \mathrm{E}-10$ & $3.570 \mathrm{E}-08$ & $1.801 \mathrm{E}-06$ & $4.096 \mathrm{E}-06$ & $3.567 \mathrm{E}-06$ & $2.360 \mathrm{E}-07$ \\
\hline $49 \mathrm{CR} 2$ & 24 & $3.185 E-05$ & $1.860 \mathrm{E}-06$ & $1.426 \mathrm{E}-07$ & $2.682 \mathrm{E}-08$ & $5.384 \mathrm{E}-09$ & 0.0 \\
\hline $50 \mathrm{TI} 2$ & 22 & 0.0 & $1.997 \mathrm{E}-13$ & $1.645 \mathrm{E}-08$ & $6.911 \mathrm{E}-07$ & $4.283 E-06$ & $9.485 \mathrm{E}-03$ \\
\hline $50 \mathrm{~V} 2$ & 23 & $4.216 \mathrm{E}-14$ & $2.513 \mathrm{E}-10$ & $1.193 \mathrm{E}-07$ & $5.498 \mathrm{E}-07$ & $7.901 \mathrm{E}-07$ & $8.848 \mathrm{E}-07$ \\
\hline $50 \mathrm{CR} 2$ & 24 & $1.619 \mathrm{E}-04$ & $1.168 \mathrm{E}-03$ & $1.157 \mathrm{E}-03$ & $4.439 \mathrm{E}-04$ & $1.546 \mathrm{E}-04$ & $5.004 \mathrm{E}-07$ \\
\hline $51 \mathrm{TI} 2$ & 22 & 0.0 & 0.0 & 0.0 & 0.0 & 0.0 & $7.297 \mathrm{E}-07$ \\
\hline $51 \mathrm{~V} 2$ & 23 & $1.929 \mathrm{E}-14$ & $9.567 \mathrm{E}-10$ & $2.634 \mathrm{E}-06$ & $2.586 \mathrm{E}-05$ & $7.256 \mathrm{E}-05$ & $4.237 \mathrm{E}-03$ \\
\hline $51 \mathrm{CR} 2$ & 24 & $3.952 \mathrm{E}-08$ & $2.498 \mathrm{E}-05$ & $3.390 E-04$ & $3.181 \mathrm{E}-04$ & $2.051 \mathrm{E}-04$ & $1.213 \mathrm{E}-05$ \\
\hline $51 \mathrm{MN} 2$ & 25 & $7.308 E-05$ & $1.481 E-05$ & $7.492 \mathrm{E}-07$ & $8.437 \mathrm{E}-08$ & $1.504 \mathrm{E}-08$ & 0.0 \\
\hline $52 \mathrm{TI} 2$ & 22 & 0.0 & 0.0 & 0.0 & 0.0 & 0.0 & $1.374 \mathrm{E}-09$ \\
\hline $52 \mathrm{~V} \quad 2$ & 23 & 0.0 & 0.0 & $1.083 E-11$ & $3.469 \mathrm{E}-10$ & $2.250 \mathrm{E}-09$ & $3.149 \mathrm{E}-06$ \\
\hline $52 \mathrm{CR} 2$ & 24 & $2.719 \mathrm{E}-09$ & $2.098 \mathrm{E}-04$ & $3.429 \mathrm{E}-02$ & $1.025 \mathrm{E}-01$ & $1.273 \mathrm{E}-01$ & $1.825 \mathrm{E}-01$ \\
\hline $52 \mathrm{MN} 2$ & 25 & $.862 \mathrm{E}-06$ & $2.018 \mathrm{E}-05$ & $1.660 \mathrm{E}-05$ & $4.580 \mathrm{E}-06$ & $1.503 \mathrm{E}-06$ & 0.0 \\
\hline $52 \mathrm{FE} 2$ & 26 & $1.469 \mathrm{E}-02$ & $5.127 \mathrm{E}-05$ & 0.0 & 0.0 & 0.0 & 0.0 \\
\hline $53 \mathrm{~V} \quad 2$ & 23 & 0.0 & 0.0 & $8.410 E-15$ & $8.600 \mathrm{E}-13$ & $1.160 \mathrm{E}-11$ & $4.044 \mathrm{E}-07$ \\
\hline $53 \mathrm{CR} 2$ & 24 & 0.0 & $7.238 \mathrm{E}-09$ & $1.779 \mathrm{E}-05$ & $1.443 \mathrm{E}-04$ & $3.732 \mathrm{E}-04$ & $1.201 \mathrm{E}-02$ \\
\hline $53 \mathrm{MN} 2$ & 25 & $4.619 \mathrm{E}-07$ & $5.477 \mathrm{E}-04$ & $7.559 \mathrm{E}-03$ & $7.317 E-03$ & $4.784 \mathrm{E}-03$ & $1.942 \mathrm{E}-04$ \\
\hline $53 \mathrm{FE} 2$ & 26 & $9.138 \mathrm{E}-04$ & $1.217 \mathrm{E}-04$ & $3.932 \mathrm{E}-06$ & $2.734 \mathrm{E}-07$ & $3.670 \mathrm{E}-08$ & 0.0 \\
\hline $54 \mathrm{CR} 2$ & 24 & 0.0 & $5.021 \mathrm{E}-11$ & $9.741 \mathrm{E}-07$ & $2.341 E-05$ & $1.209 \mathrm{E}-04$ & $6.805 E-02$ \\
\hline $54 \mathrm{MN} 2$ & 25 & $6.489 E-11$ & $3.804 \mathrm{E}-07$ & $5.049 \mathrm{E}-05$ & $1.354 \mathrm{E}-04$ & $1.830 \mathrm{E}-04$ & $1.465 \mathrm{E}-04$ \\
\hline $54 \mathrm{FE} 2$ & 26 & $.661 \mathrm{E}-02$ & $6.091 \mathrm{E}-01$ & $2.459 \mathrm{E}-01$ & $5.624 \mathrm{E}-02$ & $1.734 \mathrm{E}-02$ & $2.082 \mathrm{E}-05$ \\
\hline $54 \mathrm{CO} 2$ & 27 & $1.676 \mathrm{E}-06$ & $2.608 \mathrm{E}-09$ & 0.0 & 0.0 & 0.0 & 0.0 \\
\hline $55 \mathrm{CR} 2$ & 24 & 0.0 & 0.0 & 0.0 & 0.0 & 0.0 & $1.043 \mathrm{E}-06$ \\
\hline $55 \mathrm{MN}$ & 25 & $1.023 \mathrm{E}-12$ & $9.243 E-08$ & $6.746 \mathrm{E}-05$ & $3.960 \mathrm{E}-04$ & $9.790 \mathrm{E}-04$ & $2.265 \mathrm{E}-02$ \\
\hline $55 \mathrm{FE} 2$ & 26 & $2.100 \mathrm{E}-05$ & $1.358 \mathrm{E}-02$ & $4.241 \mathrm{E}-02$ & $2.281 \mathrm{E}-02$ & $1.263 \mathrm{E}-02$ & $2.562 \mathrm{E}-04$ \\
\hline $55 \mathrm{CO} 2$ & 27 & $1.307 \mathrm{E}-02$ & $3.244 \mathrm{E}-03$ & $6.530 \mathrm{E}-05$ & $4.413 \mathrm{E}-06$ & $6.967 \mathrm{E}-07$ & 0.0 \\
\hline $56 \mathrm{CR} 2$ & 24 & 0.0 & 0.0 & 0.0 & 0.0 & 0.0 & $3.738 \mathrm{E}-08$ \\
\hline $56 \mathrm{MN} 2$ & 25 & 0.0 & 0.0 & 2.781 & $5.539 \mathrm{~F}$ & $3.172 \mathrm{~F}$ & $1.766 \mathrm{E}-05$ \\
\hline $56 \mathrm{FE} 2$ & 26 & $1.853 \mathrm{E}-07$ & $1.564 \mathrm{E}-02$ & $5.362 E-01$ & 7. $383 \mathrm{E}-01$ & $7.721 \mathrm{E}-01$ & $4.425 \mathrm{E}-01$ \\
\hline $56 \mathrm{CO} 2$ & 27 & $.207 \mathrm{E}-04$ & $7.888 \mathrm{E}-04$ & $1.411 \mathrm{E}-04$ & $2.226 \mathrm{E}-05$ & $6.304 \mathrm{E}-06$ & $1.998 \mathrm{E}-09$ \\
\hline $56 \mathrm{NI} 2$ & 28 & $.604 \mathrm{E}-01$ & $4.622 \mathrm{E}-03$ & $7.301 \mathrm{E}-06$ & $1.387 \mathrm{E}-07$ & $1.086 \mathrm{E}-08$ & 0.0 \\
\hline $57 \mathrm{MIJ} 2$ & 25 & .0 & 0.0 & $1.818 \mathrm{E}-12$ & $8.895 \mathrm{E}-11$ & $9.776 \mathrm{E}-10$ & $1.238 \mathrm{E}-05$ \\
\hline $57 \mathrm{FE} 2$ & 26 & 0.0 & $9.760 E-08$ & $3.077 \mathrm{E}-05$ & $1.203 \mathrm{E}-04$ & $2.790 \mathrm{E}-04$ & $3.786 \mathrm{E}-03$ \\
\hline $57 \mathrm{CO} 2$ & 27 & $2.945 E-06$ & $6.210 \mathrm{E}-03$ & $1.465 \mathrm{E}-02$ & $5.948 \mathrm{E}-03$ & $3.181 \mathrm{E}-03$ & $4.028 \mathrm{E}-05$ \\
\hline $57 \mathrm{NI}$ & 28 & $1.847 \mathrm{E}-02$ & $5.470 \mathrm{E}-03$ & $6.244 \mathrm{E}-05$ & $2.485 E-06$ & $3.047 \mathrm{E}-07$ & 0.0 \\
\hline $58 \mathrm{FE} 2$ & 26 & 0.0 & $5.071 \mathrm{E}-09$ & $2.566 \mathrm{E}-05$ & $3.14 \mathrm{lE}-04$ & $1.293 \mathrm{E}-03$ & $1.755 \mathrm{E}-01$ \\
\hline $58 \mathrm{CO}$ & 27 & $2.668 \mathrm{E}-11$ & $6.386 \mathrm{E}-07$ & $1.788 \mathrm{E}-05$ & $1.921 \mathrm{E}-05$ & $2.159 \mathrm{E}-05$ & $5.234 \mathrm{E}-06$ \\
\hline $58 \mathrm{NI}$ & 28 & $1.972 E-02$ & $3.293 E-01$ & $4.390 \mathrm{E}-02$ & $5.083 E-03$ & $1.417 \mathrm{E}-03$ & $6.819 \mathrm{E}-07$ \\
\hline $58 \mathrm{CU}$ & 29 & $4.769 \mathrm{E}-10$ & 0.0 & 0.0 & 0.0 & 0.0 & 0.0 \\
\hline $59 \mathrm{FE}$ & 26 & 0.0 & 0.0 & $1.323 \mathrm{E}-11$ & $5.587 \mathrm{E}-10$ & $5.320 \mathrm{E}-09$ & $1.676 E-05$ \\
\hline $59 \mathrm{CO}$ & 27 & 0.0 & $6.279 \mathrm{E}-07$ & $1.597 \mathrm{E}-04$ & $5.533 E-04$ & $1.182 \mathrm{E}-03$ & $5.952 \mathrm{E}-03$ \\
\hline $59 \mathrm{NI}$ & 28 & $2.932 \mathrm{E}-06$ & $2.182 \mathrm{E}-03$ & $2.353 E-03$ & $7.059 \mathrm{E}-04$ & $3.842 \mathrm{E}-04$ & $2.634 \mathrm{E}-06$ \\
\hline $59 \mathrm{CU}$ & 29 & $8.372 \mathrm{E}-08$ & $5.213 E-08$ & 0.0 & 0.0 & 0.0 & 0.0 \\
\hline $60 \mathrm{FE}$ & 26 & 0.0 & 0.0 & 0.0 & 0.0 & 0.0 & $1.133 \mathrm{E}-05$ \\
\hline $60 \mathrm{CO}$ & 27 & 0.0 & 0.0 & $2.582 \mathrm{E}-09$ & $2.809 E-08$ & $1.376 \mathrm{E}-07$ & $1.661 \mathrm{E}-05$ \\
\hline $60 \mathrm{NI}$ & 28 & $1.664 \mathrm{E}-07$ & $7.636 \mathrm{E}-03$ & $7.034 \mathrm{E}-02$ & $5.793 \mathrm{E}-02$ & $5.429 \mathrm{E}-02$ & $1.054 \mathrm{E}-02$ \\
\hline $60 \mathrm{CU}$ & 29 & 3. $344 \mathrm{E}-09$ & $7.896 \mathrm{E}-08$ & 0.0 & 0.0 & 0.0 & 0.0 \\
\hline $60 \mathrm{ZN}$ & 30 & 1. $283 \mathrm{E}-08$ & $1.873 \mathrm{E}-10$ & 0.0 & 0.0 & 0.0 & 0.0 \\
\hline 6100 & 27 & 0.0 & 0.0 & $1.375 E-10$ & $.3 .935 E-09$ & $3.517 \mathrm{E}-08$ & $8.818 \mathrm{E}-05$ \\
\hline $61 \mathrm{NI}$ & 28 & 0.0 & $2.726 \mathrm{E}-07$ & $2.099 \mathrm{E}-05$ & $4.506 \mathrm{E}-05$ & $8.940 \mathrm{E}-05$ & $3.866 \mathrm{E}-04$ \\
\hline $61 \mathrm{CU}$ & 29 & $4.333 E-09$ & $5.533 \mathrm{E}-06$ & $2.192 \mathrm{E}-06$ & $5.582 \mathrm{E}-07$ & $2.548 \mathrm{E}-07$ & 0.0 \\
\hline $61 \mathrm{ZN}$ & 30 & $1.285 \mathrm{E}-09$ & $1.009 \mathrm{E}-09$ & 0.0 & 0.0 & 0.0 & 0.0 \\
\hline $62 \mathrm{CO}$ & 27 & 0.0 & 0.0 & 0.0 & 0.0 & 0.0 & $3.833 E-09$ \\
\hline $62 \mathrm{NI}$ & 28 & 0.0 & $9.143 \mathrm{E}-08$ & $9.369 \mathrm{E}-05$ & $5.128 \mathrm{E}-04$ & $1.604 \mathrm{E}-03$ & $6.110 \mathrm{E}-02$ \\
\hline $62 \mathrm{CU} 2$ & 29 & $6.801 \mathrm{E}-14$ & $6.189 \mathrm{E}-09$ & $2.463 E-08$ & $1.535 \mathrm{E}-08$ & $1.550 \mathrm{E}-08$ & 0.0 \\
\hline $62 \mathrm{zN}$ & 30 & $2.730 \mathrm{E}-08$ & $6.980 \mathrm{E}-07$ & $2.341 \mathrm{E}-08$ & $1.625 \mathrm{E}-09$ & $3.932 \mathrm{E}-10$ & 0.0 \\
\hline $63 \mathrm{CO}$ & 27 & 0.0 & 0.0 & 0.0 & 0.0 & 0.0 & $6.165 \mathrm{E}-09$ \\
\hline $63 \mathrm{NI}$ & 28 & 0.0 & 0.0 & $9.131 \mathrm{E}-11$ & $1.647 \mathrm{E}-09$ & $1.194 \mathrm{E}-08$ & $1.068 \mathrm{E}-05$ \\
\hline $63 \mathrm{CU}$ & 29 & 0.0 & $3.016 \mathrm{E}-08$ & 1.93 & $3.129 \mathrm{E}-06$ & $5.005 E-06$ & $3.924 \mathrm{E}-06$ \\
\hline $63 \mathrm{ZN}$ & 30 & $7.098 \mathrm{E}-12$ & $1.203 \mathrm{E}-08$ & $3.692 \mathrm{E}-09$ & $6.444 \mathrm{E}-10$ & $2.856 \mathrm{E}-10$ & 0.0 \\
\hline $64 \mathrm{NI}$ & 28 & 0.0 & 0.0 & $3.976 \mathrm{E}-11$ & $1.764 \mathrm{E}-09$ & $2.265 E-08$ & 2.802 \\
\hline $64 \mathrm{CU}$ & 29 & 0.0 & $2.041 \mathrm{E}-13$ & $1.300 \mathrm{E}-10$ & $6.335 \mathrm{E}-10$ & $2.286 \mathrm{E}$ & $4.324 \mathrm{E}-$ \\
\hline $64 \mathrm{ZN}$ & 30 & $5.375 \mathrm{E}-12$ & $4.591 \mathrm{E}-07$ & $1.634 \mathrm{E}-06$ & $7.128 \mathrm{E}-07$ & $5.759 \mathrm{E}-0$ & $2.300 \mathrm{E}-08$ \\
\hline $65 \mathrm{NI}$ & 28 & 0.0 & 0.0 & 0.0 & 0.0 & 0.0 & $2.950 \mathrm{E}-09$ \\
\hline $65 \mathrm{CU}$ & 29 & 0.0 & 0.0 & 1. $736 \mathrm{E}-10$ & $2.137 \mathrm{E}-09$ & $1.387 \mathrm{E}-08$ & $6.148 \mathrm{E}-06$ \\
\hline $65 \mathrm{ZN}$ & 30 & 0.0 & $5.108 \mathrm{E}-11$ & $1.504 \mathrm{E}-09$ & $1.693 \mathrm{E}-09$ & $2.875 E-09$ & $2.035 E-09$ \\
\hline $66 \mathrm{NI}$ & 28 & 0.0 & 0.0 & 0.0 & 0.0 & 0.0 & $1.502 \mathrm{E}-08$ \\
\hline $66 \mathrm{CU}$ & 29 & 0.0 & 0.0 & 0.0 & 0.0 & 0.0 & $1.068 \mathrm{E}-09$ \\
\hline $66 \mathrm{ZN}$ & 30 & 0.0 & $7.687 \mathrm{E}-11$ & $2.112 \mathrm{E}-08$ & $5.950 \mathrm{E}-08$ & $1.632 \mathrm{E}-07$ & $2.069 \mathrm{E}-06$ \\
\hline $67 \mathrm{CU}$ & 29 & 0.0 & 0.0 & 0.0 & 0.0 & 0.0 & $6.798 E-09$ \\
\hline $67 \mathrm{ZN}$ & 30 & 0.0 & 0.0 & 0.0 & 0.0 & 0.0 & $3.335 E-09$ \\
\hline $68 \mathrm{ZN}$ & 30 & 0.0 & 0.0 & 0.0 & 0.0 & 0.0 & $1.926 \mathrm{E}-07$ \\
\hline $69 \mathrm{GA}$ & 31 & 0.0 & 0.0 & 0.0 & 0.0 & 0.0 & 0.0 \\
\hline $70 \mathrm{ZN}$ & 30 & 0.0 & 0.0 & 0.0 & 0.0 & 0.0 & 0.0 \\
\hline $70 \mathrm{GA}$ & 31 & 0.0 & 0.0 & 0.0 & 0.0 & 0.0 & 0.0 \\
\hline $71 \mathrm{GA}$ & 31 & 0.0 & 0.0 & 0.0 & 0.0 & 0.0 & 0.0 \\
\hline
\end{tabular}


what can be accomplished with them (which is a weakness, since iron-peak nucleosynthesis may well require a particle-rich freeze-out component).

We note here that the nuclear reaction network used to calculate the frozen abundances did not include excited states of nuclei, mainly because their crosssections are generally not known. Our NSE calculations do include excited states. Hainebach (1973) has given simple parametric fits to the nuclear partition functions that we used. However, the effect of including excited states in NSE calculations is small, especially at lower temperatures. Most major nuclei are even- $A$, even- $Z$ species with no low-lying excited states, and are negligibly affected by their inclusion.

The solutions of the nuclear network are expensive and were not originally calculated with interpolation in mind. As a result we have only the eight runs listed in table 1, and have chosen to interpolate the abundances at intermediate values of $\eta$ by taking advantage of the fact that (inexpensively generated) NSE compositions at $T_{9}=3, \rho=10^{7} \mathrm{~g} \mathrm{~cm}^{-3}$ are good approximations to particle-poor freeze-out compositions computed by network evolution. The information contained in NSE versus $\eta$ curves was used in the interpolation scheme.

The interpolation was done in the following manner. Let $\ln X(\eta)$ represent the logarithm of the nucleon fraction of some nucleus of a frozen composition as a frozen composition as a function of $\eta$. We know these from the expansions for only eight values of $\eta$. Similarly, let $\ln X_{e}(\eta)$ be the NSE (equilibrium) abundances at a temperature $T_{9}=3$ as a function of $\eta$. These can be quickly calculated for a large number of $\eta$ 's. Then to interpolate $\ln X$ between two known points $\eta_{i}$ and $\eta_{i+1}$ (see fig. 1), we fix the interpolated $\ln X(\eta)$ to lie at the same distance above the secant connecting its values at $\eta_{i}$ and $\eta_{i+1}$ as the value of

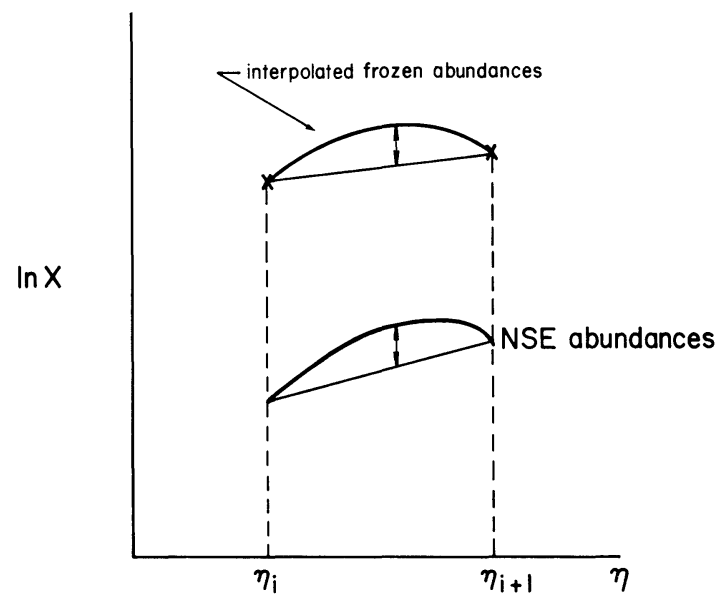

FIG. 1.-Interpolation scheme for frozen abundances as a function of $\eta$, combining data from expansions at two of the eight calculated points (crosses at $\eta_{1}$ and $\eta_{i+1}$ ) with NSE abundances (lower curve). The interpolation scheme gives the upper curve between the two crosses by adding to the upper secant the difference between the NSE curve and its secant. ln $X_{e}(\eta)$ lies above its corresponding secant. The interpolation scheme is therefore

$$
\begin{aligned}
& \ln X(\eta)=\ln X_{e}(\eta) \\
& -\left[\ln X_{e}\left(\eta_{i}\right)+\frac{\ln X_{e}\left(\eta_{i+1}\right)-\ln X_{e}\left(\eta_{i}\right)}{\left(\eta_{i+1}-\eta_{i}\right)}\left(\eta-\eta_{i}\right)\right] \\
& +\left[\ln X\left(\eta_{i}\right)+\frac{\ln X\left(\eta_{i+1}\right)-\ln X\left(\eta_{i}\right)}{\left(\eta_{i+1}-\eta_{i}\right)}\left(\eta-\eta_{i}\right)\right],
\end{aligned}
$$

where the terms in brackets are the two secants. This scheme behaves well and maintains the general form of the NSE curves.

In the regions of $\eta$ where a nucleus had negligible abundance, and so was not included in the nuclearburning network, we used NSE abundances adjusted by the formula

$$
\ln X(\eta)=\ln X_{e}(\eta)+\left[\ln X\left(\eta_{i}\right)-\ln X_{e}\left(\eta_{i}\right)\right]
$$

in order to maintain continuity. Here $\eta_{i}$ is the nearest of the eight calculated points.

The interpolated abundance curves are shown in figure 4 , which will be described below in $\S$ IVb).

\section{MIXING COMPOSITIONS OF DIFFERENT NEUTRON EXCESSES; SEARCH FOR COMPOSITIONS SIMILAR TO THE SOLAR SYSTEM COMPOSITION}

We have constructed a computer-implemented algorithm to search automatically for interpolated frozen compositions, as functions of neutron excess, and linear combinations of these which approximate the solar-system composition or some designated subset thereof. A set of abundance ratios (e.g., ${ }^{56} \mathrm{Fe} /{ }^{54} \mathrm{Fe}$, etc.) chosen at will is part of the program's input data, and it is these ratios that the program tries to fit to the corresponding solar abundance ratios.

We define $x_{i}^{k} \equiv x_{i}\left(\eta^{k}\right)$ as the nucleon fraction of nucleus $i$ in a frozen composition characterized by neutron excess $\eta^{k}$. We also refer to such a composition as a "zone at $\eta^{k}$.",

A mixture of several zones is formed by taking a quantity $n^{k}$ nucleons from each zone $k$, i.e., $n^{1}$ from zone 1 , etc., with total number $N=\sum_{k} n^{k}$. Then the nucleon fraction $X_{i}$ of species $i$ in the mixture is $X_{i}=$ $\sum_{k} n^{k} x_{i}^{k} / N$. The fraction of the mixture taken from zone $k$ is defined: $f^{k} \equiv n^{k} / N$. Note that $f^{k} \geq 0$ and $\sum_{k} f^{k}=1$. Then $X_{i}=\sum_{k} f^{k} x_{i}^{k}=\sum_{k} f^{k} x_{i}\left(\eta^{k}\right)$. Thus the composition of the mixture is a function of the neutron excess of each zone, $\eta^{k}$, and of the fraction of the mixture, $f^{k}$, which each zone contributes. For any composition $X$, we further define the notation $R_{i j}(X) \equiv$ $\ln \left(X_{i} / X_{j}\right)$.

Now let $X$ be a frozen composition for which all radioactive nuclei with short half-lives have decayed. In particular $\beta$-radioactive nuclei have decayed to their $\beta$-stable isobars. Let $S$ be the solar-system composition which we currently take as the table of Cameron (1973). Let $D_{i j} \equiv R_{i j}(X)-R_{i j}(S)$ and let $D$ be the set of $D_{i j}$ for all $i$ and $j$. For the purposes of fitting it 
is useful to define a positive definite quadratic form $Q$ on $D$,

$$
Q(D) \equiv \sum_{i>j} \omega_{i j} D_{i j}^{2} / T
$$

where $\omega_{i j} \geq 0$ and $T$ is the number of terms in the sum for which $\omega_{i j} \neq 0$. The $\omega$ 's are arbitrary weighting factors, having values on the order of unity, which are used to emphasize the importance of certain abundance ratios, or to delete them by setting their $\omega_{i j}=0$. $Q(D)=0$ if and only if $D_{i j}=0$ for all $i j$ for which $\omega_{i j} \neq 0$, i.e., if and only if the constructed composition exactly matches the solar composition for the ratios of the nuclei chosen to be matched.

We choose the number of zones (one or more) which a model will contain. A function-minimization program using the method of conjugate gradients (FMCG from the IBM Scientific Subroutine Package) then iterates on the $\eta^{k}$ and $f^{k}$ of all the zones until $Q$ is minimized. This produces a kind of $\chi^{2}$ fit, except that the weighting factors $\omega_{i j}$ are arbitrary rather than being determined by the error bars in the solar abundances.

Because of the uncertainty in elemental abundance ratios, we have chosen in most of our calculations to match only isotopic abundance ratios. We then set $\omega=1$ for those isotopic ratios being fit and $\omega=0$ for all other abundance ratios. When we do include transelemental ratios, we usually set $\omega$ (transelemental) $=1$ and $\omega$ (isotopic) $=2$.

We expect the $e$-process to synthesize only the iron peak; we therefore fit only abundance ratios of ironpeak nuclei. We wish to make as many of these as possible, without making too much of any nucleus. If the process which makes the bulk of ${ }^{56} \mathrm{Fe}$ (the most abundant iron-peak nucleus) overproduces some other nucleus, then it is probably not possible to eliminate the excess. On the other hand, an underproduced nucleus might be accounted for by adding material from another zone or another nucleosynthesis process which produces it, but very little ${ }^{56} \mathrm{Fe}$.

\section{RESULTS}

\section{a) The Fowler and Hoyle (1964) Solution}

If one seeks to reproduce the abundance of only the four stable iron isotopes, ${ }^{54,56,57,58} \mathrm{Fe}$, using only one zone, one finds the solution shown in figure 2, which is virtually identical to the solution found by Fowler and Hoyle (1964). The frozen abundances of most nuclei are, however, smaller relative to ${ }^{56} \mathrm{Fe}$ than the NSE abundances used by Fowler and Hoyle.

The program found a best fit at $\eta=0.0707$, just below the neutron excess of ${ }^{56} \mathrm{Fe}$. One therefore expects, correctly, that the mass 56 in this composition is synthesized almost exclusively as ${ }^{56} \mathrm{Fe}$. This solution does quite well in reproducing the solar abundances of ${ }^{50,51} \mathrm{~V},{ }^{54} \mathrm{Cr},{ }^{55} \mathrm{Mn},{ }^{54,56,57,58} \mathrm{Fe},{ }^{59} \mathrm{Co}$, and ${ }^{62} \mathrm{Ni}$. There are, however, unacceptable (factor of 10) overproductions of ${ }^{52,53} \mathrm{Cr}$ and ${ }^{60} \mathrm{Ni}$, as well as a troublesome underproduction of ${ }^{58} \mathrm{Ni}$. These overproductions, which were not apparent in 1964, appear, now because of the higher solar abundance of ${ }^{56} \mathrm{Fe}$ resulting from a reevaluation of solar spectroscopicdata (Garzand Kock 1969), in agreement with the meteoritic abundance derived from type I carbonaceous chondrites (Cameron 1968). One must conclude, because of the overproductions by a factor of 10 , that no more than about onetenth of the solar system's ${ }^{56} \mathrm{Fe}$ could be due to the process which produced this composition.

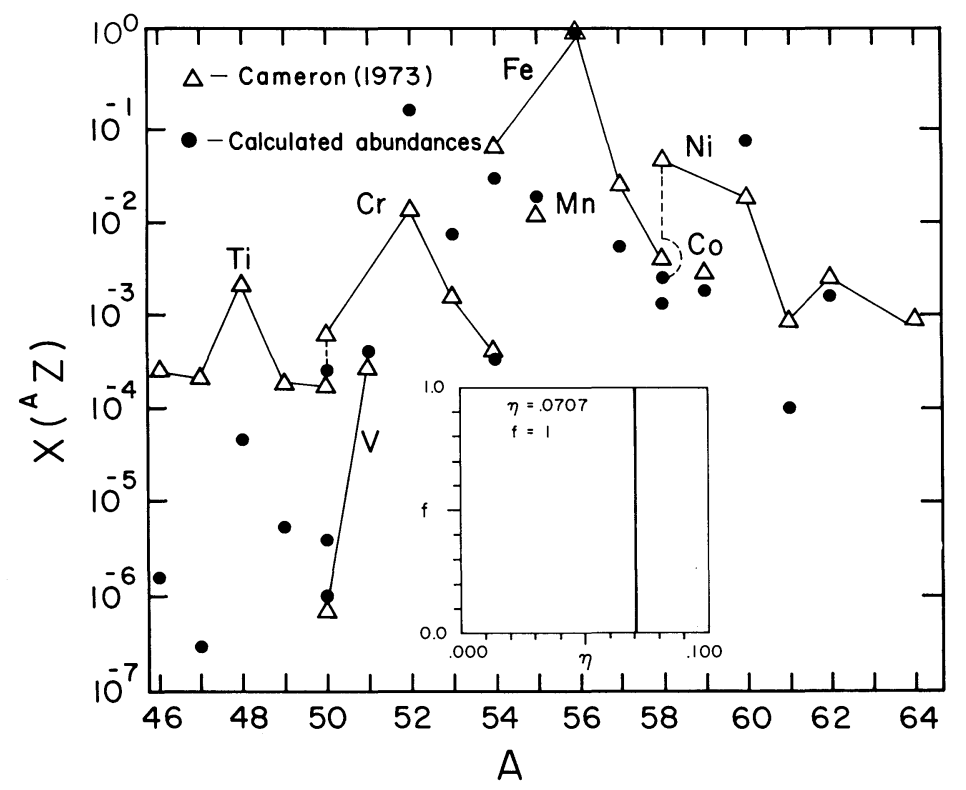

FIG. 2.-One-zone high- $\eta$ solution. Normal freeze-out abundances (after $\beta$-decay) and the Cameron (1973) solar abundances are shown, each normalized to ${ }^{56} \mathrm{Fe}$. The insets in figs. $2,3,5$, and 6 show the $\eta$ and $f$ of the contributing zones. Missing calculated abundances are off scale, less than $10^{-7}$. Isotopic ratios of ${ }^{54,56,57,58} \mathrm{Fe}$ were fitted, with weighting factors $\omega=1$. 
We emphasize that this conclusion is based on our assumed knowledge of the elemental abundances of chromium and nickel relative to iron. If the solar system $\mathrm{Cr} / \mathrm{Fe}$ and $\mathrm{Ni} / \mathrm{Fe}$ ratios were 10 times higher than they are currently thought to be (and reevaluations of such magnitude have ample precedent) then the argument would not apply. However, the problem of the underproduction of ${ }^{58} \mathrm{Ni}$ would remain and would even be intensified.

An alternative solution synthesizing ${ }^{56,57} \mathrm{Fe}$ as ${ }^{56,57} \mathrm{Ni}$ at lower $\eta$ has, on the other hand, no disqualifying overproductions or underproductions relative to currently accepted solar abundances. Before we discuss this alternative, however, we will consider the possibility that the Fowler and Hoyle solution can be salvaged by adjusting the physical conditions which determine the composition.

Because lower temperatures cause more narrowly peaked NSE abundance distributions (more matter in the most abundant nucleus, less in the others), we might hope that the $\mathrm{Cr}$ and $\mathrm{Ni}$ overproductions in the "wings" of the iron peak could be removable. Let us estimate a freeze-out temperature capable of reducing the NSE overproductions of $\mathrm{Cr}$ and $\mathrm{Ni}$ relative to $\mathrm{Fe}$ from a factor of 10 to a factor of no more than 3, a reasonable error bar in the elemental abundance determinations. The nuclear Saha equation restricts the ratios of number densities to values satisfying

$\frac{n\left({ }^{52} \mathrm{Cr}\right)}{n\left({ }^{56} \mathrm{Fe}\right)} \frac{n\left({ }^{60} \mathrm{Ni}\right)}{n\left({ }^{56} \mathrm{Fe}\right)}$

$$
\begin{aligned}
= & \left(\frac{\omega_{52} \omega_{60}}{\omega_{56}{ }^{2}}\right)\left(\frac{m_{52} m_{60}}{m_{56}{ }^{2}}\right)^{3 / 2} \\
& \times \exp \left(Q_{52}+Q_{60}-2 Q_{56} / k T\right),
\end{aligned}
$$

where $\omega, m$, and $Q$ are, respectively, the nuclear partition function, mass, and binding energy. This product of abundance ratios is a function of temperature only. These three nuclei have only high-lying excited states that can be ignored at the temperatures of interest. Then the temperature dependence of $\omega$ vanishes, and one can solve explicitly for temperature. Setting the $\mathrm{Cr} / \mathrm{Fe}$ and $\mathrm{Ni} / \mathrm{Fe}$ abundance ratios equal to 3 times their solar values, one finds that $T_{9}=2.4$, and by calculating a few NSE distributions one finds that at $\rho=10^{7} \mathrm{~g} \mathrm{~cm}^{-3}$ the ratios ${ }^{52} \mathrm{Cr} /{ }^{56} \mathrm{Fe}$ and ${ }^{60} \mathrm{Ni} /{ }^{56} \mathrm{Fe}$ are each about 3 times their solar values near the neutron excess of ${ }^{56} \mathrm{Fe}$, which is $\eta=(30-26) / 56=0.071$. The solar ratios are reached only at $T_{9}=1.8$.

These temperatures are rather low for maintaining NSE if one envisages stellar material expanding and cooling off to such a temperature after an explosion has pushed the temperature above $T_{9}=5$. A run with our nuclear-burning network shows that at $T_{9}=2.4$, an approach to equilibrium requires about threefourths of a year, compared with explosive time scales of $1 \mathrm{~s}$. Even if one could eliminate the Cr and Ni overproductions by an approach to NSE at a low temperature, the other nuclei which are in such good agreement with their solar abundances in figure 2 would become badly underabundant. The possibility is therefore both implausible and unattractive. So given the current $\mathrm{Cr}: \mathrm{Fe}: \mathrm{Ni}$ ratios, one must indeed eliminate the $\eta=$ 0.071 composition as a major source of the solar system's ${ }^{56} \mathrm{Fe}$.

\section{b) One-Zone, Low- $\eta$ Solution}

Given a single zone, we used the function miminization program to vary $\eta$ to find a composition which after $\beta$-decays approximated the solar ratios of the

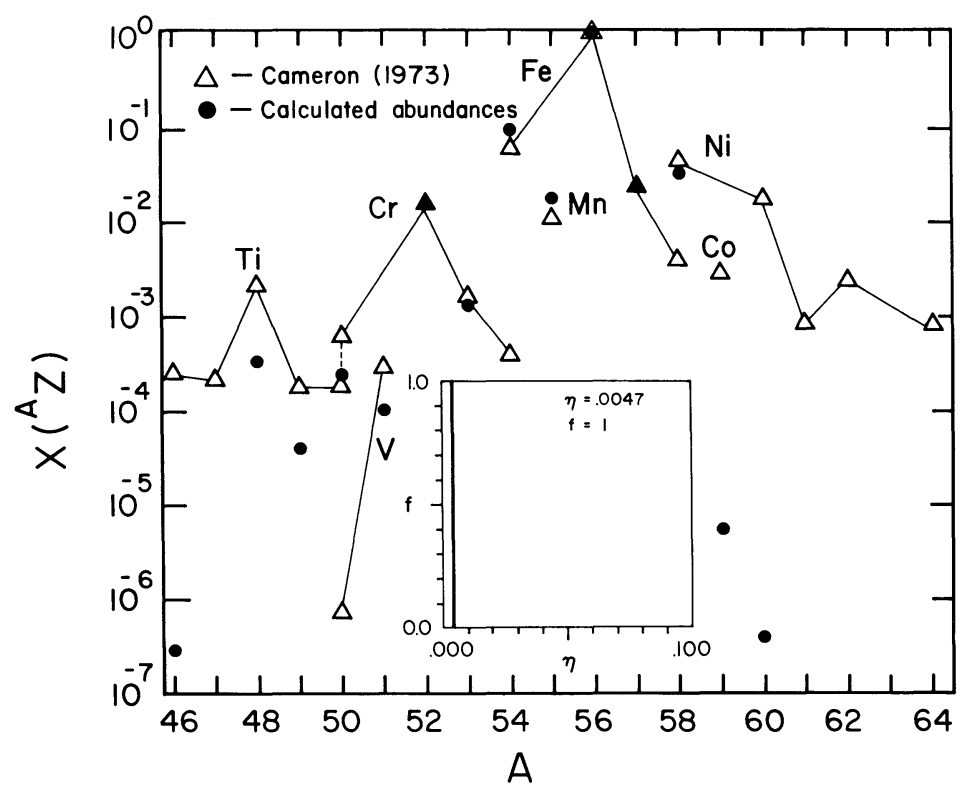

FIG. 3.-One-zone low- $\eta$ solution. Similar to fig. 2. Isotopic and transelemental ratios of ${ }^{52,53} \mathrm{Cr},{ }^{54,56,57} \mathrm{Fe}$, and ${ }^{58} \mathrm{Ni}$ were fitted, with $\omega$ (isotopic) $=2, \omega($ transelemental $)=1$. 

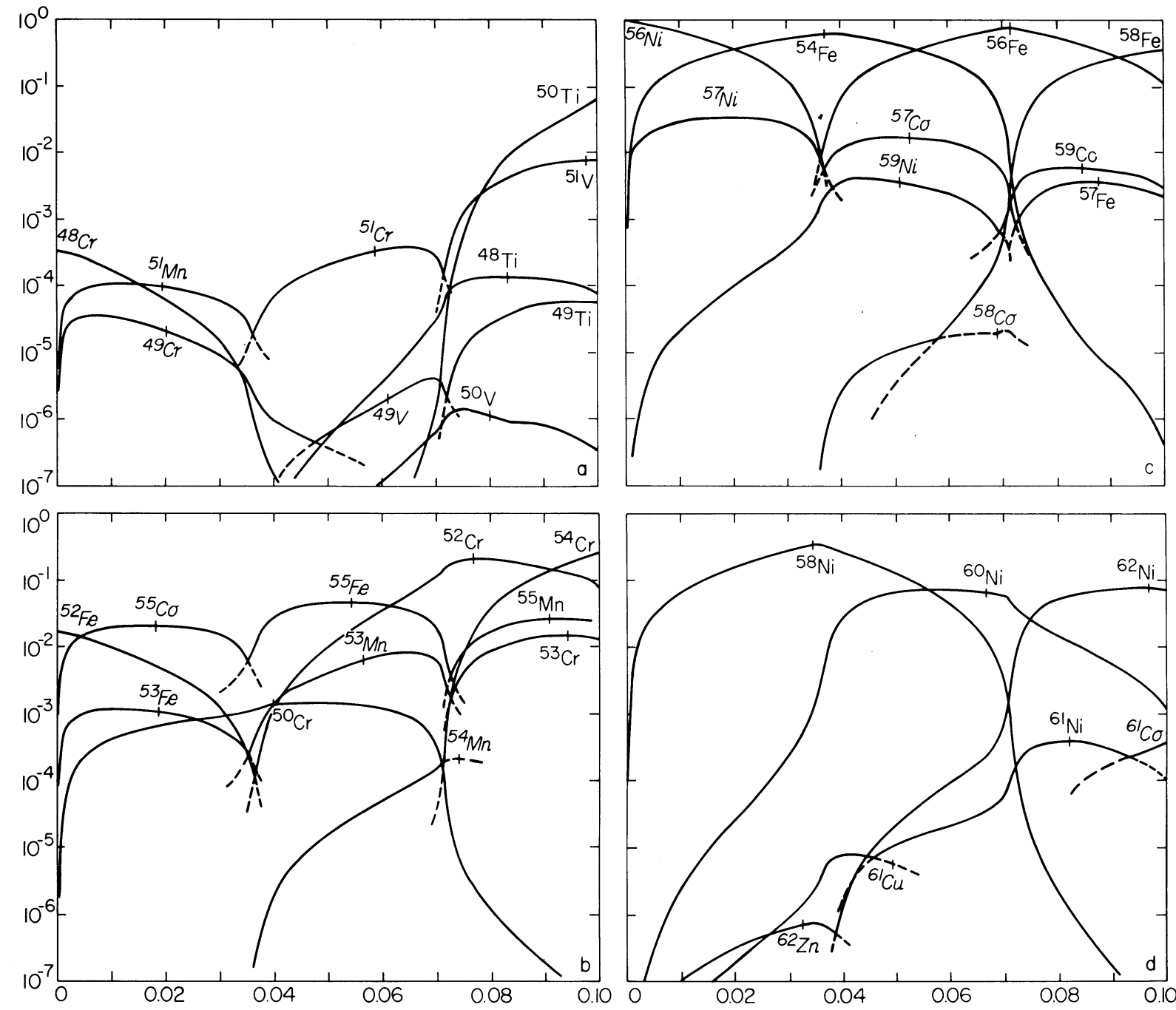

$\eta$

FIG. 4.-Interpolated particle-poor freeze-out abundances as a function of $\eta$ in the range $0<\eta<0.1$, before $\beta$-decay. Curves are solid lines where the nucleus is the primary progenitor of a stable nucleus, and are dashed or omitted elsewhere. All labels of $\beta$-radioactive species are in italics. A small vertical line marks the $\eta$ of each nucleus, if it is on scale. $(a)$ Curves for progenitors of ${ }_{48,49,50} \mathrm{Ti}$ and ${ }^{50,51} \mathrm{~V}$; $(b)$ curves for progenitors of ${ }^{50,52,53,54} \mathrm{Cr}$ and ${ }^{55} \mathrm{Mn},(c)$ curves for progenitors of ${ }^{54,56,57,58} \mathrm{Fe}$ and ${ }^{59} \mathrm{Co},(d)$ curves for progenitors of ${ }^{58,60,61,62} \mathrm{Ni}$.

species ${ }^{52,53} \mathrm{Cr},{ }^{54,56,57} \mathrm{Fe}$, and ${ }^{58} \mathrm{Ni}$. Both transelemental and isotopic ratios were used, the isotopic ratios receiving twice the weight $(\omega=2)$ that the transelemental ratios received $(\omega=1)$. The best fit occurred at $\eta=0.0047$ (see fig. 3). The fitted ratios were well reproduced, as well as the abundances of several other species, viz., ${ }^{48,49} \mathrm{Ti}$ and ${ }^{50} \mathrm{Cr}$ (all somewhat underabundant) and ${ }^{55} \mathrm{Mn}$.

Noticeably underproduced are the species ${ }^{50} \mathrm{Ti}$, ${ }^{54} \mathrm{Cr},{ }^{58} \mathrm{Fe},{ }^{59} \mathrm{Co}$, and ${ }^{60,61,62} \mathrm{Ni}$. How might these nuclei be produced? Let us examine how the abundances (nucleon fractions) of the stable iron-peak nuclides vary with $\eta$ in normal freeze-out compositions, before and after $\beta$-decay. This is shown in figure
4. These abundance curves are spread onto four graphs, each containing the curves of all nuclei that contribute significantly to four or five stable nuclei. Each curve is drawn as a solid line in the region of $\eta$ where it is the primary source, after any $\beta$-decay, of a stable nucleus. It is drawn as a dashed line in other regions, or may be omitted entirely if its abundance is much lower than that of another progenitor of its stable isobar daughter.

A curve is labeled in italics if the nucleus is unstable. Each curve is marked by a small vertical line at the value of $\eta$ equal to that of the nucleus itself. It is seen that the abundance of almost every nucleus peaks at or near its own $\eta$. A careful examination of NSE abundances shows that for them, the displacement of 


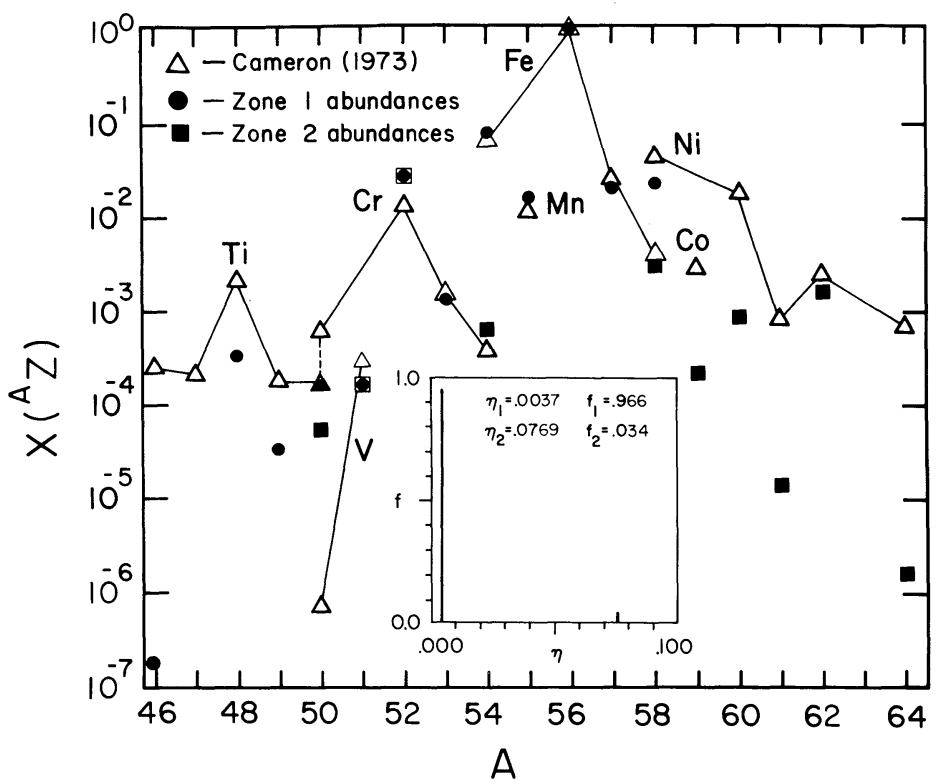

Fig. 5.-Two-zone solution. Similar to fig. 2, except that the solid circles show the nuclei produced primarily in the low- $\eta$ zone (1), and the solid squares, the high- $\eta$ zone (2). ${ }^{51} \mathrm{~V}$ and ${ }^{52} \mathrm{Cr}$ (combined circles and squares) are produced by both zones in nearly equal amounts. Isotopic abundances of ${ }^{52,53,54} \mathrm{Cr},{ }^{54,56,57,58} \mathrm{Fe}$, and ${ }^{58,62} \mathrm{Ni}$ were fitted, with $\omega=1$.

the maximum is never more than about 0.005 in $\eta$. Agreement is almost as good for the interpolated frozen abundance curves. However, noticeably large discrepancies in this rule can be seen in figure 4 , with a maximum displacement of $\Delta \eta=0.018$ for ${ }^{49} \mathrm{Cr}$.

The abundances after $\beta$-decay are obtained by adding together the abundances of all parent nuclei. It is clear that this addition is necessary in practice only near the intersection of two solid curves of the same isobar. In most places one isobar is clearly dominant. We shall usually be referring to the abundance curves of all parent isobars of a stable nucleus when we refer to the abundance curve of a stable nucleus.

The abundance curves in figure 4 show the underproduction of ${ }^{50} \mathrm{Ti},{ }^{54} \mathrm{Cr},{ }^{58} \mathrm{Fe},{ }^{59} \mathrm{Co}$, and ${ }^{60,61,62} \mathrm{Ni}$ at low $\eta$. They also reveal that the abundances of these nuclei increase by many orders of magnitude at higher $\eta$. For masses 50, 54, and 58, each of which have two stable isobars (plus the nearly stable ${ }^{50} \mathrm{~V}$ ), it is seen that at lower $\eta$ the parent nuclei which produce the low- $\eta$ nuclei ${ }^{50} \mathrm{Cr},{ }^{54} \mathrm{Fe}$, and ${ }^{58} \mathrm{Ni}$ are favored. At higher $\eta$ the parent nuclei which produce the high- $\eta$ species ${ }^{50} \mathrm{Ti},{ }^{54} \mathrm{Cr}$, and ${ }^{58} \mathrm{Fe}$ are favored. Truran $(1972)$ demonstrated that these last three species have solar abundances consistent with a neutron-rich (high- $\eta$ ) $e-$ process event. Our search for the best two-zone model finds this solution also.

\section{c) Two-Zone Solution}

To see what might be accomplished with two zones, we first asked for a two-zone fit to the isotopic ratios of the three nuclei ${ }^{54,56,57} \mathrm{Fe}$, produced in the one-zone low- $\eta$ solution, and of the nucleus ${ }^{58} \mathrm{Fe}$, expected to be produced in a high- $\eta$ zone. The program found a low- $\eta$ zone, essentially identical to the one-zone low- $\eta$ solution, and added a small amount of a high- $\eta$ zone which produced the nuclei ${ }^{50} \mathrm{Ti},{ }^{54} \mathrm{Cr},{ }^{58} \mathrm{Fe}$, and ${ }^{62} \mathrm{Ni}$.

We then refined this solution by asking for a twozone fit of all the isotopic ratios of the nuclei a twozone fit seemed capable of producing. We thus fitted the three isotopic ratios of ${ }^{52,53,54} \mathrm{Cr}$ (viz., ${ }^{53} \mathrm{Cr} /{ }^{52} \mathrm{Cr}$, ${ }^{54} \mathrm{Cr} /{ }^{53} \mathrm{Cr}$, and ${ }^{54} \mathrm{Cr} /{ }^{53} \mathrm{Cr}$ ), the six isotopic ratios of ${ }^{54,56,57,58} \mathrm{Fe}$, and the one isotopic ratio of ${ }^{58,62} \mathrm{Ni}$. It was found that the redundancy of including every possible isotopic ratio helped the program to converge. This refined two-zone solution occured at $\eta_{1}=0.0037$, $f^{1}=0.966$ and $\eta_{2}=0.0769, f^{2}=0.034$, and is shown in figure 5. The contribution of each zone to each $\beta$-stable nucleus is indicated in the figure.

\section{d) Three-Zone Solution}

In the mass range $48 \leq A \leq 62$, the two-zone solution leaves underproductions of several nuclei, the most serious of which are ${ }^{50} \mathrm{~V},{ }^{59} \mathrm{Co},{ }^{60} \mathrm{Ni}$, and ${ }^{61} \mathrm{Ni}$. Could a third zone produce any of these ? The one-zone high- $\eta$ solution, with its overproduction of ${ }^{60} \mathrm{Ni}$ is a candidate. If we add ${ }^{60} \mathrm{Ni}$ to the list of nuclei already fitted, we have the set ${ }^{52,53,54} \mathrm{Cr},{ }^{54,56,57,58} \mathrm{Fe}$, and $58,60,62 \mathrm{Ni}$. When the function minimization program is asked to fit all the isotopic ratios of this set with three zones, it finds the solution shown in figure 6 and table 2 .

The table lists 22 stable iron-peak nuclei. Asterisks denote nuclei appearing in the ratios being fitted. Numbered columns (1), (2), and (3) show the contribution of each zone to the total calculated abundance of each nucleus. The $\eta$ and $f$ (fractional contribution) of each zone is listed above its column. The numbers 


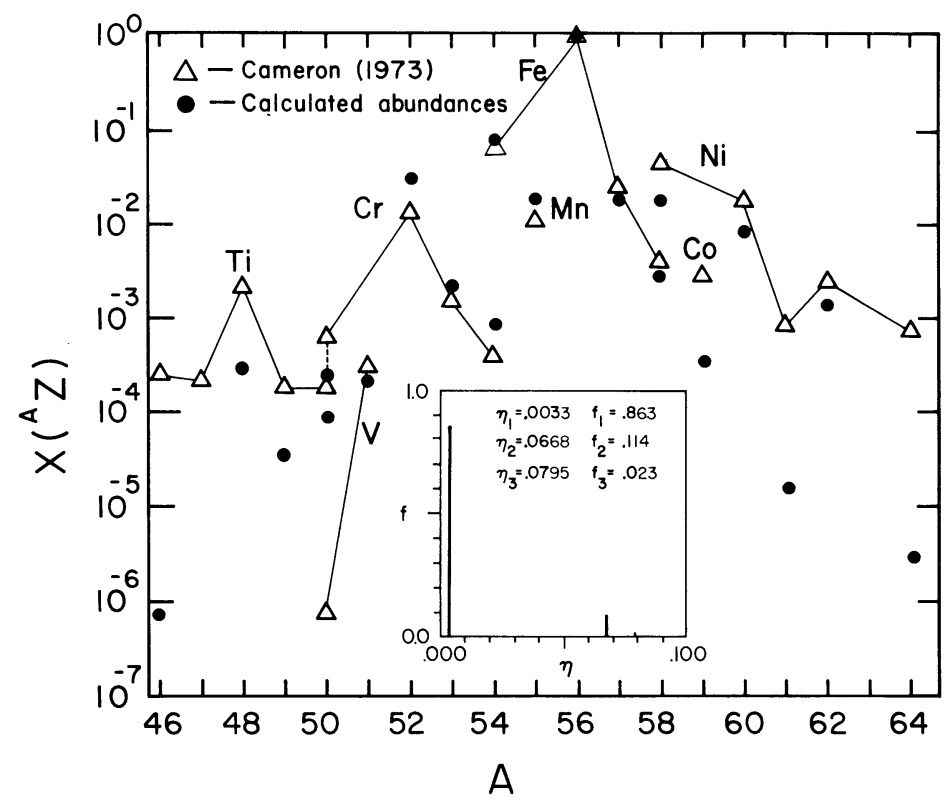

FIG. 6.-Three-zone solution. Similar to fig. 2. All calculated abundances are shown as solid circles. The contribution from each zone is tabulated in table 2 . Isotopic ratios of ${ }^{52,53,54} \mathrm{Cr},{ }^{54,56,57,58} \mathrm{Fe}$, and ${ }^{58,60,62} \mathrm{Ni}$ were fitted with $\omega=1$.

TABLE 2

Yield Normalized to Total $X\left({ }^{56} \mathrm{Fe}\right)$

\begin{tabular}{|c|c|c|c|c|c|c|}
\hline & $\begin{array}{c}n_{1}=.0033 \\
f_{1}=.863 \\
i\end{array}$ & $\begin{array}{c}n_{2}=.0668 \\
f_{2}=.114 \\
2\end{array}$ & $\begin{array}{c}n_{3}=.0795 \\
f_{3}=.023 \\
3\end{array}$ & MIX & SOLAR & $M / S)$ \\
\hline $46 \mathrm{TI}$ & $58 \mathrm{E}-07$ & 7 & 0 & 07 & 4 & -2.541 \\
\hline $47 \mathrm{TI}$ & $2.53 \mathrm{E}-08$ & $4.23 E-08$ & $2.04 \mathrm{E}-09$ & $6.96 E-08$ & $2.23 E-04$ & -3 \\
\hline $48 \mathrm{TI}$ & $3.04 \mathrm{E}-04$ & $1.92 \mathrm{E}-06$ & $51 E-06$ & $3.09 \mathrm{E}-04$ & $2.31 \mathrm{E}-03$ & -0.873 \\
\hline $49 \mathrm{TI}$ & $3.05 E-05$ & 7 & 7 & 5 & -04 & - \\
\hline $50 \mathrm{TI}$ & $2.78 \mathrm{E}-21$ & $2.53 \mathrm{E}-08$ & $.89 \mathrm{E}-05$ & $8.89 \mathrm{E}-05$ & $1.74 \mathrm{E}-04$ & -029 \\
\hline $50 \mathrm{~V}$ & -14 & 8 & $10 \Gamma-$ & $7.88 \mathrm{E}$ & $7.39 \mathrm{E}-07$ & -0.972 \\
\hline $51 \mathrm{~V}$ & $7.02 \mathrm{E}-05$ & 5.22 & $7.03 \mathrm{E}-05$ & $1.91 \mathrm{E}-04$ & $3.12 \mathrm{E}-04$ & -0.214 \\
\hline $50 \mathrm{CR}$ & $1.44 \mathrm{E}-04$ & $9.80 \mathrm{E}-05$ & $3.66 \mathrm{E}-08$ & $2.42 \mathrm{E}-04$ & $6.42 \mathrm{E}-04$ & -0 . \\
\hline$\star 52 \mathrm{CR}$ & $1.52 \mathrm{E}-02$ & $1.01 \mathrm{E}-02$ & $5.40 \mathrm{E}-03$ & $3.07 \mathrm{E}-02$ & $1.29 \mathrm{E}-02$ & 0.376 \\
\hline$\star 53 \mathrm{CR}$ & $8.78 E-04$ & $1.14 \mathrm{E}-03$ & $2.31 E-04$ & $2.25 \mathrm{E}-03$ & $1.50 \mathrm{E}-03$ & 0.176 \\
\hline * $54 \mathrm{CR}$ & $5.00 \mathrm{E}-11$ & $1.51 \mathrm{E}-05$ & $8.54 \mathrm{E}-04$ & $8.70 \mathrm{E}-04$ & $3.83 \mathrm{E}-04$ & 0.356 \\
\hline $55 \mathrm{MN}$ & $1.26 \mathrm{E}-02$ & $4.22 \mathrm{E}-03$ & $4.43 \mathrm{E}-04$ & $1.73 \mathrm{E}-02$ & $1.20 \mathrm{E}-02$ & 0.158 \\
\hline * $54 \mathrm{FE}$ & $5.96 \mathrm{E}-02$ & $1.48 \mathrm{E}-02$ & $1.79 \mathrm{E}-06$ & $7.43 E-02$ & $6.12 \mathrm{E}-02$ & 0.084 \\
\hline$\star 56 \mathrm{FE}$ & $8.92 \mathrm{E}-01$ & $9.28 \mathrm{E}-02$ & $1.50 \mathrm{E}-02$ & $1.00 \mathrm{E}+00$ & $1.00 \mathrm{E}+00$ & -0.000 \\
\hline$\star 57 \mathrm{FE}$ & $1.78 \mathrm{E}-02$ & $1.21 \mathrm{E}-03$ & $8.12 \mathrm{E}-05$ & $1.91 \mathrm{E}-02$ & $2.43 \mathrm{E}-02$ & -0.105 \\
\hline *58FE & $2.07 E-11$ & $1.97 \mathrm{E}-05$ & $2.97 \mathrm{E}-03$ & $2.99 E-03$ & $3.73 E-03$ & -0.096 \\
\hline $59 \mathrm{CO}$ & $2.53 \mathrm{E}-06$ & $2.06 \mathrm{E}-04$ & $1.58 \mathrm{E}-04$ & $3.66 \mathrm{E}-04$ & $3.06 \mathrm{E}-03$ & -0.922 \\
\hline *58NI & $1.77 \mathrm{E}-02$ & $1.66 \mathrm{E}-03$ & $6.70 \mathrm{E}-08$ & $1.94 E-02$ & $4.44 \mathrm{E}-02$ & -0.360 \\
\hline *60NI & $1.46 \mathrm{E}-07$ & $8.65 E-03$ & $4.33 E-04$ & $9.09 \mathrm{E}-03$ & $1.77 \mathrm{E}-02$ & -0.291 \\
\hline $61 \mathrm{NI}$ & $4.87 \mathrm{E}-09$ & $4.72 \mathrm{E}-06$ & $1.08 \mathrm{E}-05$ & $1.55 E-05$ & $8.17 \mathrm{E}-04$ & -1.721 \\
\hline${ }^{\star} 62 \mathrm{NI}$ & $2.46 \mathrm{E}-08$ & $3.57 E-05$ & $1.33 \mathrm{E}-03$ & $1.37 \mathrm{E}-03$ & $2.56 \mathrm{E}-03$ & -0.272 \\
\hline $64 \mathrm{NI}$ & $6.01 \mathrm{E}-21$ & $8.26 \mathrm{E}-11$ & $2.75 E-06$ & $2.75 E-06$ & $7.78 \mathrm{E}-04$ & -2.452 \\
\hline
\end{tabular}


shown in the numbered columns are the product of the nucleon fraction $\left(x_{j}^{i}\right)$ of each nucleus $j$ in zone $i$ (after $\beta$-decay) and the $f^{i}$ of the zone $i$, divided by the sum over zones of this quantity for the nucleus ${ }^{56} \mathrm{Fe}$, i.e., $f^{i} x_{j}{ }^{i} / \sum_{k} f^{k} x_{56}{ }^{k}$. [The denominator is the total $X\left({ }^{56} \mathrm{Fe}\right)$ in the mixture and $=0.844$. Summing these quantities over all zones gives the total abundance of the nucleus in the mixture normalized to ${ }^{56} \mathrm{Fe}$ and is shown in the column labeled MIX. The column labeled SOLAR shows the nucleon fractions, relative to ${ }^{56} \mathrm{Fe}$, of the Cameron (1973) solar abundances. The column labeled LOG $(M / S)$ is $\log _{10}$ (MIX/SOLAR).

The first zone has $\eta_{1}=0.0033, f^{1}=0.863$ similar to zone one of the two-zone solution, but with a slightly lower fractional contribution, down from $f=0.966$. The third zone has $\eta_{3}=0.0695, f^{3}=0.023$, similar to the second zone of the two-zone solution, but again a smaller fractional contribution, down from $f=0.034$. The remaining mass has gone into the second zone which has $\eta_{2}=0.0668, f^{2}=0.114$. This $\eta$ is only slightly below the $\eta=0.0707$ of the one-zone high- $\eta$ solution. The abundance graphs in figure 4 show that this is a region of rapidly changing abundances, due to the peaking of ${ }^{56} \mathrm{Fe}$ at its own neutron excess $\eta\left({ }^{56} \mathrm{Fe}\right)=$ 0.0714 . As this $\eta$ is approached, mass consolidates into ${ }^{56} \mathrm{Fe}$. Because of this rapid change, there are in some cases large differences in abundances between $\eta=$ 0.0707 and $\eta=0.0668$. Nevertheless, the abundance ratios are, grossly speaking, similar. In particular, the overabundances of ${ }^{52,53} \mathrm{Cr}$, and especially ${ }^{60} \mathrm{Ni}$, remain. The result is that when the three zones are added together, the isotopic ratios among the nuclei being fitted are very well produced. The nuclei ${ }^{50} \mathrm{Ti}$ and ${ }^{55} \mathrm{Mn}$ are also close to their Cameron (1973) transelemental ratios to ${ }^{56} \mathrm{Fe}$.

\section{e) Other Nuclei, Other Zones}

There remains the possibility of improving the fit for those nuclei now being fitted by allowing the three zones to become more than three, say six. That is, one or more of the three zones found may be a compromise among several zones over a small range of $\eta$ which could produce a better fit than the one zone can. This was tried. The three zones were broken up into six, each initially with half the mass of the zone it came from, and separated from its neighbor by $\Delta \eta=0.001$; e.g., the first zone at $\eta=0.0033, f=0.863$ became two zones at $\eta=0.0028, f=0.4315$ and $\eta=0.0038$, $f=0.4315$. The result was that zones 1 and 2 coalesced into the old zone 1 , zones 3 and 4 into the old zone 2 , and zones 5 and 6 into the old zone 3 . The six zones degenerated into the original three. This seems to us to be a significant result and not merely a numerical happenstance of the symmetric subdivisions of the original zones. To test the validity of this procedure, we tried it on another problem to which we knew the answer; namely, the three-zone fit described in $\S$ IVd to the isotopes of $\mathrm{Cr}, \mathrm{Fe}$, and $\mathrm{Ni}$. We first asked the program to calculate the best two-zone fit. Faced with the difficulty of having ${ }^{60} \mathrm{Ni}$ among the nickel isotopes to be fitted, the code found the best two-zone com- promise: $\eta_{1}=0.0044, f^{1}=0.825$ and $\eta_{2}=0.0729$, $f^{2}=0.175$. This compromise failed by a factor of 3 in the ${ }^{60} \mathrm{Ni} /{ }^{62} \mathrm{Ni}$ ratio and overproduced ${ }^{52} \mathrm{Cr}$ by a factor of 4 . We then took the higher- $\eta$ zone and divided it into two equal $(f=0.0875)$ high- $\eta$ zones at $\eta_{2}=$ 0.0724 and 0.0734 each just $\Delta \eta=0.0005$ from the two-zone solution. We used these three zones as the starting point for a three-zone fit with the code, and it resulted in identically the same three zones already described in $\S I V d$. Thus the small symmetric displacements do not seem to inhibit the code from finding a better solution when one exists.

We accordingly conclude that the three-zone solution for the isotopic ratios being fitted is not a compromise, but the best that can be done with any number of zones, given the Cameron (1973) abundances.

Next we ask if we can make any iron-peak nucleus that is underproduced in the three-zone solution. The most promising candidate is ${ }^{48} \mathrm{Ti}$ whose isotopic ratio to ${ }^{50} \mathrm{Ti}$ is underabundant by only a factor of 3 or 4 . If we were to correct this ratio by adding ${ }^{48} \mathrm{Ti}$, it would be necessary to bring its abundance up to about $10^{-3}$ relative to ${ }^{56} \mathrm{Fe}$. This seems not to be possible, because figure $4 a$ shows that the highest ${ }^{48} \mathrm{Ti}$ abundance occurs at $\eta=0$, where its parent ${ }^{48} \mathrm{Cr}$ has a mass fraction of about $3 \times 10^{-4}$, giving ${ }^{48} \mathrm{Ti} /{ }^{56} \mathrm{Fe} \simeq 4 \times 10^{-4}$, which is not enough.

The only alternative for improving the $\mathrm{Ti}$ isotopic ratios is to drive down the abundance of ${ }^{50} \mathrm{Ti}$. When the three-zone model was rerun with isotopic ratios to ${ }^{48} \mathrm{Ti}$ included, that is exactly what happened. The ${ }^{48,49,50} \mathrm{Ti}$ isotopic ratios were much better but they were all underabundant relative to ${ }^{56} \mathrm{Fe}$ by factors ranging from 4 to 8 , which are probably unacceptable errors, even for transelemental ratios. So we give up trying to make ${ }^{48} \mathrm{Ti}$ with these particle-poor freeze-out compositions. The correct origin of ${ }^{48} \mathrm{Ti}$ is somewhat of a question mark. It is synthesized in silicon burning along with many nuclei in the iron peak, so if that process is the origin of ${ }^{48} \mathrm{Ti}$, it follows that the ironpeak abundances to be fitted by our approach will have to be modified accordingly (Bodansky et al. 1968; Woosley et al. 1973).

The remaining underproductions in the mass range 48-62 in the three-zone solution are of the species ${ }^{49} \mathrm{Ti},{ }^{50} \mathrm{~V},{ }^{50} \mathrm{Cr},{ }^{59} \mathrm{Co}$, and ${ }^{61} \mathrm{Ni}$, all underabundant by about an order of magnitude.

Figure $4 a$ shows that ${ }^{49} \mathrm{Ti} /{ }^{56} \mathrm{Fe}$ is nowhere larger than its solar system value of $1.76 \times 10^{-4}$. We conclude that it is not possible for these models to produce ${ }^{49} \mathrm{Ti}$.

Figure $4 a$ also shows that ${ }^{50} \mathrm{~V} /{ }^{51} \mathrm{~V}$, whose solar ratio is about $5 \times 10^{-3}$, is about right only at $\eta \simeq 0.070$. But in the three-zone solution, the two high- $\eta$ zones are far enough away from this $\eta$ that the ${ }^{50} \mathrm{~V} /{ }^{51} \mathrm{~V}$ ratio is too low in each. When these are diluted by ${ }^{51} \mathrm{~V}$ from the low $-\eta$ zone, the underabundance of ${ }^{50} \mathrm{~V}$ results. Nowhere is there an overabundance of ${ }^{50} \mathrm{~V}$ which might be added to make up the deficiency.

As far as ${ }^{50} \mathrm{Cr}$ is concerned, the ${ }^{50,52,53} \mathrm{Cr}$ isotopic ratios are exactly right at $\eta \simeq 0.007$. There are even 
overproductions of ${ }^{50} \mathrm{Cr}$ (underproduced in the threezone solution) in the region $0.02 \geqslant \eta \geqslant 0.05$ (see fig. $4 a$ ). The problem with this ${ }^{50} \mathrm{Cr}$ source is that ${ }^{54} \mathrm{Fe}$ is overproduced in this region, as figure $4 c$ shows. Therefore the bulk of the mixture cannot come from this region. A four-zone model was run including the nuclei fit in the three zone solution plus ${ }^{50} \mathrm{Cr}$. Only isotopic ratios were fitted. It found the solution $\eta_{1}=0.0039$, $f^{1}=0.709, \eta_{2}=0.0043, f^{2}=0.098, \eta_{3}=0.0554$, $f^{3}=0.156, \eta_{4}=0.0767, f^{4}=0.036$, which are four distinct zones. Most of the ${ }^{50} \mathrm{Cr}$ came from zones 3 and 1 . However ${ }^{50} \mathrm{Cr} /{ }^{52} \mathrm{Cr}$ was still too small by a factor of 3, while ${ }^{54} \mathrm{Fe} /{ }^{56} \mathrm{Fe}$ was too large by a factor of 2 . We feel that this worsening of the ${ }^{54} \mathrm{Fe} /{ }^{56} \mathrm{Fe}$ ratio is not sufficiently compensated for by the better ${ }^{50} \mathrm{Cr} /{ }^{52} \mathrm{Cr}$ ratio, although it is a point worth remembering. Since oxygen burning can produce ${ }^{50} \mathrm{Cr}$ (Woosley et al. 1973), its production here may even be undesirable.

As for ${ }^{59} \mathrm{Co}$, figure 4 shows that ${ }^{59} \mathrm{Co}$ can be overproduced relative to ${ }^{56} \mathrm{Fe}\left(\right.$ solar ratio $\left.=3.06 \times 10^{-3}\right)$ only in the regions $0.039 \leqslant \eta \leqslant 0.055$ and $0.072 \leqslant$ $\eta \leqslant 0.100$. However, contributions from these regions sufficient to produce ${ }^{59} \mathrm{Co}$ are prohibited by overproductions of ${ }^{54} \mathrm{Fe}$ and ${ }^{58} \mathrm{Fe}$, respectively, as figure $4 c$ indicates. Similarly figure $4 d$ shows that ${ }^{61} \mathrm{Ni}$ is not overproduced relative to ${ }^{56} \mathrm{Fe}$ anywhere in the region $0<\eta<0.1$. It thus seems that the particle-poor freeze-out is not the source of these two nuclei, although the particle-rich freeze-out may be (Woosley et al. 1973, see fig. 23).

That there is little or no contribution from intermediate neutron excess material, $0.005 \leq \eta \leq 0.065$, is dictated by the solar abundances of ${ }^{54} \mathrm{Fe}$ and ${ }^{57} \mathrm{Fe}$. The large overabundance of ${ }^{54} \mathrm{Fe}$ in this region could only be compensated for (see fig. $4 c$ ) by lowering the $\eta$ of the low $-\eta$ material and/or raising the $\eta$ of the high- $\eta$ material. But this also has the effect of reducing the ${ }^{57} \mathrm{Fe}$ abundance, and this is not compensated for by the intermediate- $\eta$ region, where ${ }^{57} \mathrm{Fe}$ is underabundant relative to ${ }^{54} \mathrm{Fe}$. The only solution is to make ${ }^{57} \mathrm{Fe}$ in about its correct abundance relative to both ${ }^{54} \mathrm{Fe}$ and ${ }^{56} \mathrm{Fe}$, and this occurs only at certain points found by the program in the low $-\eta$ and high $-\eta$ regions. This statement is of course sensitive to the basic assumptions of this paper. Both ${ }^{54} \mathrm{Fe}$ and ${ }^{57} \mathrm{Fe}$ may in fact be due in part to other modes of nucleosynthesis, in which case the demands we are making on our $e$ process model are unrealistic. If so, however, it is even more essential to avoid those $\eta$ 's resulting in overabundance of ${ }^{54} \mathrm{Fe}$.

\section{f) Elemental Abundances}

Let us define $[\Xi] \equiv(\Xi / \mathrm{Fe}) /(\Xi / \mathrm{Fe})_{\odot}$, where $\Xi$ represents the chemical symbol of some element, and the chemical symbol is notation for total nucleon fraction, summed over all isotopes of that element. (Note that our definition of $[\Xi]$ is not logarithmic.) The use of only the information contained in isotopic ratios has resulted in our obtaining the following elemental abundance ratios (from the three-zone solution), rela- tive to their Cameron (1973) solar ratios: $[\mathrm{V}]=0.61$, $[\mathrm{Cr}]=2.2,[\mathrm{Mn}]=1.4,[\mathrm{Fe}]=1.01$, and $[\mathrm{Ni}]=$ 0.45 . The corresponding values for the two-zone solution are $[\mathrm{V}]=0.49,[\mathrm{Cr}]=1.75,[\mathrm{Mn}]=1.27,[\mathrm{Fe}]=$ 1.01 , and $[\mathrm{Ni}]=0.37$. Since these numbers are within the probable error bars of the solar-system elemental abundance determinations, we count this as an encouraging success of our models. We also have $[\mathrm{Ti}]=0.14$ and $[\mathrm{Co}]=0.12$ for the three-zone solution, and $[\mathrm{Ti}]=0.14$ and $[\mathrm{Co}]=0.07$ for the twozone solution. We interpret this to mean that the bulk of the solar system's titanium and cobalt was not produced by the particle-poor $e$-process.

Although all of these elemental ratios result from fitting isotopic ratios only, they undergo little improvement when transelemental ratios are also fitted. For example, in a two-zone model in which the transelemental ratios ${ }^{52} \mathrm{Cr}:{ }^{56} \mathrm{Fe}:{ }^{58} \mathrm{Ni}$ were included and were given greater weighting factors than isotopic ratios, some small improvement in transelemental ratios was noted compared to the two-zone solution of $\S$ IVc. The ratio ${ }^{58} \mathrm{Ni} /{ }^{56} \mathrm{Fe}$ was almost exactly right; however ${ }^{52} \mathrm{Cr} /{ }^{56} \mathrm{Fe}$ was slightly worse! Isotopic ratios suffered. We conclude that the particle-poor freeze-out abundances, which are capable of matching isotopic ratios rather well, cannot reproduce the Cameron (1973) elemental abundance ratios. We also recall that our attempt to match the ${ }^{52} \mathrm{Cr}:{ }^{56} \mathrm{Fe}:{ }^{60} \mathrm{Ni}$ ratios, detailed in $\S$ IVa, produced severely low yields of other isotopes of these elements.

\section{SUMMARY AND CONCLUSIONS}

The solar system's iron-peak material may be synthesized by a mixture of $e$-process compositions in a low- $\eta$ region, $\eta \simeq 0.003$ and a high- $\eta$ region, $0.065 \leq \eta \leq 0.080$, with at least 85 percent of the material coming from the low $-\eta$ region. There is little or no contribution from intermediate zones. One low- $\eta$ zone (fig. 3) can produce the nuclei ${ }^{52,53} \mathrm{Cr},{ }^{55} \mathrm{Mn}$, ${ }^{54,56,57} \mathrm{Fe}$, and ${ }^{58} \mathrm{Ni}$.

The addition of one high- $\eta$ zone (fig. 5) adds the nuclei ${ }^{50} \mathrm{Ti},{ }^{51} \mathrm{~V},{ }^{54} \mathrm{Cr},{ }^{58} \mathrm{Fe}$, and ${ }^{62} \mathrm{Ni}$.

The addition of another high- $\eta$ zone (fig. 6) adds only the nucleus ${ }^{60} \mathrm{Ni}$ and contributes about half of the ${ }_{52,53} \mathrm{Cr}$ abundances.

The $e$-process fails by approximately an order of magnitude to produce enough ${ }^{48,49} \mathrm{Ti},{ }^{50} \mathrm{Cr},{ }^{50} \mathrm{~V}$, or ${ }^{61} \mathrm{Ni}$ in their solar isotopic ratios, or ${ }^{59} \mathrm{Co}$ in its solar elemental ratio.

The failures of this approach may be understood in a quite straightforward way. To obtain perfect fits with our code it would first have been necessary to subtract the nuclear abundances due to all other processes of nucleosynthesis. These are not independently known. The entire problem is iterative, and we regard the present investigation as establishing what the particlepoor $e$-process can accomplish by itself.

This dilemma is most easily understood by noting that the addition of a third zone added only one nucleus to the list of those correctly fitted, and that that nucleus $\left({ }^{60} \mathrm{Ni}\right)$ is one of those synthesized along 
with ${ }^{59} \mathrm{Co}$ and ${ }^{60,61,62} \mathrm{Ni}$ in the particle-rich freeze-out (see fig. 23 of Woosley et al. 1973). Since only ${ }^{62} \mathrm{Ni}$ of these four can be synthesized in our two-zone fits, and since only ${ }^{60} \mathrm{Ni}$ can be added by going to a three-zone fit, the abundance evidence for a particle-rich freezeout seems to have gained some strength. The correct solution is further clouded by the possibility that ${ }^{59} \mathrm{Co}$ and ${ }^{61} \mathrm{Ni}$ may be due in part to weak $s$-processes (Peters et al. 1972). In any case, it seems that only our two-zone fits should be regarded as being seriously suggested by the abundances, with the three-zone fit simply a possibility.

A similar problem exists on the low- $A$ side of the iron peak, where we find that ${ }^{48} \mathrm{Ti}$ is not produced in quite adequate amounts. This may be related even to the problem of ${ }^{44} \mathrm{Ca}$, for which no adequate source has yet been found. If some $\alpha$-capture chain (e.g., either silicon-burning quasi-equilibrium or a direct flow) is responsible, it will probably also contribute to other nuclei in the iron peak, necessitating yet another presently unknown subtraction before the methods of this paper will work perfectly.

Even if we have correctly assumed that the nuclei whose abundance ratios we are attempting to fit are entirely due to the particle-poor $e$-process, and given that our three-zone solution is the best that can be done with three or more zones, we must still ask whether other superpositions, which may look noticeably different as far as the $\eta$ 's and $f$ 's of each zone are concerned, may still give a negligibly different fit to the abundance ratios.

For any solution, we could in principle define a range of acceptable variation in the abundance ratios and then find the corresponding domain in the $\eta$ 's and $f$ 's. This could be done with the same or a different number of zones. For the class of $n$-zone models there are $2 n-1$ free parameters (the $f$ 's sum to 1 ), so for $n>1$, the search required to define the domain becomes impractical.

As an example of this problem we constructed a four-zone superposition yielding essentially identical abundances to those of the best three-zone fit of $\S \mathrm{IV} d$, but which is significantly different in its distribution in $\eta$ and $f$. The parameters chosen were $\eta_{1}=$
$0.0021, f^{1}=0.628, \eta_{2}=0.0096, f^{2}=0.190, \eta_{3}=$ $0.0678, f^{3}=0.142$, and $\eta_{4}=0.0765, f^{4}=0.040$. The major differences are that there are two high- $\eta$ zones contain 32 percent more mass than the corresponding two zones of the three-zone fit. Because the resulting abundances were, to the eye, scarcely different from the three-zone abundances of figure 6 , we learn that considerable caution must be used when deriving physical conclusions from the details of a "best fit" in $\eta$ and $f$.

On a more positive note, the two-zone solution provides an adequate description of 12 nuclear abundances in terms of only three parameters. This success is much greater than the older $e$-process solution (Fowler and Hoyle 1964), suggesting that it is largely correct. It will be interesting to see if calculations in stellar evolution can identify the origins of these two zones and clarify whether a third zone or a particlerich freeze-out (or both) also occur.

On another positive note, the origins of more than 80 percent, say, of ${ }^{56,57} \mathrm{Fe}$ seem surely to be in ${ }^{56,57} \mathrm{Ni}$, whatever the resolution of the above uncertainties. Thus the prospects for the future of nuclear $\gamma$-ray line astronomy (Clayton $1973 a, b ; 1974)$ appear bright. These nickel isotopes must be ejected on a hydrodynamic time too short to allow $\eta$ to increase beyond the range of those values found for our low- $\eta$ zones. This means explosive ejection. Identification of these $\gamma$-ray lines could provide a big observational breakthrough for these issues of nucleosynthesis.

We thank Professors William A. Fowler and Raymond J. Talbot, Jr., for many helpful conversations on this problem. Thanks also to Professor Sir Fred Hoyle and the Institute of Theoretical Astronomy, Cambridge, England, for a generous grant of computer time while this research was in preparation. K. L. Hainebach thanks the Fannie and John Hertz Foundation for a graduate fellowship during much of the research period. The research was supported in part by the National Science Foundation under GP-18335 and GP-32051 and in part by the National Aeronautics and Space Administration under NGR-44-006-159.

\section{REFERENCES}

Arnett, W. D., Truran, J. W., and Woosley, S. E. 1971, Ap. J., 165, 87.

Bodansky, D., Clayton, D. D., and Fowler, W. A. 1968, Ap.J. Suppl., 16, 299, No. 148.

Burbidge, E. M., Burbidge, G. R., Fowler, W. A., and Hoyle, F. 1957, Rev. Mod. Phys., $29,547$.

Cameron, A. G. W. 1968, Origin and Distribution of the Elements, ed. L. H. Ahrens (Oxford: Pergamon Press), p. 125.

Cameron, A. G. W. 1973, Space Sci. Rev., 15, 121.

Clayton, D. D. 1973 a, in Explosive Nucleosynthesis, ed. D. N. Schramm and W. D. Arnett (Austin: University of Texas Press), p. 264.

. 1973 , in Gamma-Ray Astrophysics, ed. F. W. Stecker and J. I. Trombka (Washington, D.C.: NASA), p. 263.

Clayton, D. D. 1974, Ap. J., 188, 155.

Clayton, D. D., and Woosley, S. E. 1969, Ap. J., 157, 1381.

Clifford, F. E., and Tayler, R. J. 1965, Mem. R.A.S., 69, Pt. 2, 21.

Fowler, W. A., and Hoyle, F. 1964, Ap. J. Suppl., 9, 201, No. 91.

Garz, G., and Kock, M. 1969, Astr. and Ap., 2, 274.

Hainebach, K. L. 1973, Ph.D. thesis, Rice University (unpublished), p. 52.

Hoyle, F. 1946, M.N.R.A.S., 106, 343.

Peters, J. G., Fowler, W. A., and Clayton, D. D., 1972, Ap.J., 173, 637.

Truran, J. W. 1972, Ap. J., 177, 453

Truran, J. W., and Arnett, W. D. 1970, Ap. J., 160, 181.

Woosley, S. E., Arnett, W. D., and Clayton, D. D. 1973, $A p$ J. Suppl., 26, 231, No. 231. 